Guido Ferretti · Marc J. Licker · Sara Anchisi

Christian Moia · Davide Susta · Denis R. Morel

\title{
The effects of $\beta 1$-adrenergic blockade on cardiovascular oxygen flow in normoxic and hypoxic humans at exercise
}

\begin{abstract}
At exercise steady state, the lower the arterial oxygen saturation $\left(\mathrm{SaO}_{2}\right)$, the lower the $\mathrm{O}_{2}$ return $\left(\dot{Q} \overline{\mathrm{v}} \mathrm{O}_{2}\right)$. A linear relationship between these variables was demonstrated. Our conjecture is that this relationship describes a condition of predominant sympathetic activation, from which it is hypothesized that selective $\beta 1$-adrenergic blockade (BB) would reduce $\mathrm{O}_{2}$ delivery $\left(\dot{Q} \mathrm{aO}_{2}\right)$ and $\dot{Q} \overline{\mathrm{v}} \mathrm{O}_{2}$. To test this hypothesis, we studied the effects of $\mathrm{BB}$ on $\dot{Q} \mathrm{aO}_{2}$ and $\dot{Q} \overline{\mathrm{v}} \mathrm{O}_{2}$ in exercising humans in normoxia and hypoxia. $\mathrm{O}_{2}$ consumption $\left(\dot{V} \mathrm{O}_{2}\right)$, cardiac output $\left(\dot{Q}, \mathrm{CO}_{2}\right.$ rebreathing), heart rate, $\mathrm{SaO}_{2}$ and haemoglobin concentration were measured on six subjects (age $25.5 \pm 2.4$ years, mass $78.1 \pm 9.0 \mathrm{~kg}$ ) in normoxia and hypoxia (inspired $\mathrm{O}_{2}$ fraction of 0.11 ) at rest and steady-state exercises of 50,100 , and $150 \mathrm{~W}$ without $(\mathrm{C})$ and with $\mathrm{BB}$ with metoprolol. Arterial $\mathrm{O}_{2}$ concentration $\left(\mathrm{CaO}_{2}\right), \dot{Q} \mathrm{aO}_{2}$, and $\dot{Q} \overline{\mathrm{v}} \mathrm{O}_{2}$ were then computed. Heart rate, higher in hypoxia than in normoxia, decreased with $\mathrm{BB}$. At each $V \mathrm{O}_{2}, \dot{Q}$ was higher in hypoxia than in normoxia. With $\mathrm{BB}$, it decreased during intense exercise in normoxia, at rest, and during light exercise in hypoxia. $\mathrm{SaO}_{2}$ and $\mathrm{CaO}_{2}$ were unaffected by BB. The $\dot{Q} \mathrm{aO}_{2}$ changes under $\mathrm{BB}$ were parallel to those in $\dot{Q} \cdot \dot{Q} \overline{\mathrm{v}} \mathrm{O}_{2}$ was unaffected by exercise in normoxia. In hypoxia the slope of the relationship between $\dot{Q}_{\mathrm{aO}}$ and $\dot{V} \mathrm{O}_{2}$ was lower than 1 , indicating a reduction of $\dot{Q} \overline{\mathrm{v}} \mathrm{O}_{2}$ with increasing workload. $\dot{Q} \overline{\mathrm{v}} \mathrm{O}_{2}$ was a linear function of $\mathrm{SaO}_{2}$ both in $\mathrm{C}$ and in BB. The line for BB was flatter than and below that for $\mathrm{C}$. The resting $\dot{Q} \overline{\mathrm{v}} \mathrm{O}_{2}$ in normoxia, lower than the corresponding exercise values, lied on the BB line. These results agree with the tested
\end{abstract}

G. Ferretti $(\varangle) \cdot$ S. Anchisi · C. Moia · D. Susta

Département de Physiologie, Centre Médical Universitaire, 1 rue Michel Servet, 1211 Geneva 4, Switzerland

E-mail: guido.ferretti@medecine.unige.ch

Tel: $+41-22-3795363$

Fax: $+41-22-3795402$

M. J. Licker · D. R. Morel

Département d'Anesthésiologie, Pharmacologie et Soins Intensifs Chirurgicaux, Hôpital Cantonal Universitaire,

1211 Geneva 4, Switzerland hypothesis. The two observed relationships between $\dot{Q} \overline{\mathrm{v}} \mathrm{O}_{2}$ and $\mathrm{SaO}_{2}$ apply to conditions of predominant sympathetic or vagal activation, respectively. Moving from one line to the other implies resetting of the cardiovascular regulation.

Keywords Oxygen delivery - Oxygen return · Autonomic nervous system $\cdot$ Exercise

\section{Introduction}

Acute polycythaemia and anaemia cause opposite changes in cardiac output $(\dot{Q})$ and in the blood flow of active skeletal muscles, which compensate for the induced changes in blood haemoglobin concentration $([\mathrm{Hb}])$, and thus in arterial oxygen concentration $\left(\mathrm{CaO}_{2}\right)$ (Ferretti et al. 1992; Koskolou et al. 1997b; Roach et al. 1999; Gonzalez-Alonso et al. 2001). As a consequence, the oxygen flow in arterial blood (oxygen delivery, $\dot{Q} \mathrm{aO}_{2}$ ) at any given metabolic level is maintained invariant. Indeed $\dot{Q a O}_{2}$ is independent of $[\mathrm{Hb}]$ and is linearly related to the exercise oxygen consumption $\left(\dot{V} \mathrm{O}_{2}\right)$. Moreover, the linear relationship between $\dot{Q} \mathrm{aO}_{2}$ and power was found to be parallel to that between $\dot{V} \mathrm{O}_{2}$ and power (Ferretti et al. 1992). This indicated that the difference between these two lines on the $y$-axis, corresponding to the oxygen flow in mixed venous blood (oxygen return, $\dot{Q} \overline{\mathrm{v}} \mathrm{O}_{2}$ ), is a constant. The value at which the constant $\dot{Q} \overline{\mathrm{v}} \mathrm{O}_{2}$ is set, however, was found to be lower if the arterial oxygen saturation $\left(\mathrm{SaO}_{2}\right)$ was lower (Koskolou et al. 1997a), despite the $\dot{Q}$ increase in acute hypoxia (Stenberg et al. 1966).

Anchisi et al. (2001) found a linear relationship between $\mathrm{SaO}_{2}$ and $\dot{Q} \overline{\mathrm{v}} \mathrm{O}_{2}$, which we interpret as applying to a condition of predominant sympathetic activation. This postulate relies on the following notions: (1) a resting human in normoxia is characterised by elevated vagal stimulation that is withdrawn at exercise start (Robinson et al. 1966; Fagraeus and Linnarsson 1976; Malliani 
et al. 1991); (2) the $\dot{Q} \overline{\mathrm{v}} \mathrm{O}_{2}$ values observed by Anchisi et al. (2001) in resting humans in normoxia fall well below the described $\mathrm{SaO}_{2}$ vs $\dot{Q} \overline{\mathrm{v}} \mathrm{O}_{2}$ line, and are significantly lower than the invariant $\dot{Q} \overline{\mathrm{v}} \mathrm{O}_{2}$ values observed at exercise in normoxia in the same study; (3) acute hypoxia depresses vagal activation (Yamamoto et al. 1996; Lucy et al. 2000; Halliwill and Minson 2002) and increases sympathetic activation (Xie et al. 2001); and (4) the $\dot{Q} \overline{\mathrm{v}} \mathrm{O}_{2}$ values observed by Anchisi et al. (2001) in resting humans in hypoxia lie on the described $\dot{Q} \overline{\mathrm{v}} \mathrm{O}_{2}$ vs $\mathrm{SaO}_{2}$ line. A direct consequence of this postulate is the hypothesis that selective blockade of heart $\beta 1$-adrenergic receptors would reduce $\dot{Q} \mathrm{aO}_{2}$ and $\dot{Q} \overline{\mathrm{v}} \mathrm{O}_{2}$ in humans at given submaximal steady state workloads, and thus change the relationship between $\dot{Q} \overline{\mathrm{v}} \mathrm{O}_{2}$ and $\mathrm{SaO}_{2}$.

However, to the best of our knowledge, no report of the effects of selective $\beta$-blockade on $\dot{Q} \mathrm{aO}_{2}$ and $\dot{Q} \overline{\mathrm{v}} \mathrm{O}_{2}$ in healthy humans exists in the literature. The few studies on the cardiorespiratory response to exercise in healthy humans after selective $\beta 1$-adrenergic blockade show contradictory results. The maximal oxygen consumption and maximal expiratory ventilation at exercise was reported to be slightly reduced in many (Van Baak et al. 1985; Kaiser et al. 1986; Verstappen and Van Baak 1987; Gullestad et al. 1988; Jilka et al. 1988; Kalis et al. 1988; Vanhees et al. 1988) but not in all studies (Ronnevik et al. 1995). Maximal cardiac output was also reduced (Pawelczyk et al. 1992), whereas cardiac output at submaximal exercise was found to be slightly reduced in some studies (Joyner et al. 1986; Kelbaek and Godtfredsen 1991; Pawelczyk et al. 1992) but not in all (Vanhees et al. 2000). Obviously enough, heart rate and systolic blood pressure were found to be systematically reduced.

We therefore decided to carry out the present study, the aim of which was to test the hypothesis formulated above that selective blockade of heart $\beta 1$-adrenergic receptors would reduce $\dot{Q} \mathrm{aO}_{2}$ and $\dot{Q} \overline{\mathrm{v}} \mathrm{O}_{2}$ in exercising humans and the relationship between $\dot{Q}_{\overline{\mathrm{v}}} \mathrm{O}_{2}$ and $\mathrm{SaO}_{2}$. To this aim, we determined the effects of selective $\beta 1$ adrenergic blockade with metoprolol on $\dot{Q} \mathrm{aO}_{2}$ and $\dot{Q} \overline{\mathrm{v}} \mathrm{O}_{2}$ in humans exercising in normoxia and in acute normobaric hypoxia.

\section{Methods}

\section{Subjects}

Six healthy young subjects took part in the experiments. They were $25.5 \pm 2.4$ years old and weighed $78.1 \pm 9.0 \mathrm{~kg}$. Their maximal oxygen consumption in normoxia was $3.66 \pm 0.24 \mathrm{lmin}^{-1}$, so that all had a maximal aerobic power above $250 \mathrm{~W}$. All had a normal resting and exercise electrocardiogram. All subjects were informed about the procedures and the potential risks of the experiments and signed an informed consent form. The local Ethical Committee approved the study, which did not foresee the performance of maximal exercise tests in hypoxia.
Measurements and calculations

$\dot{V} \mathrm{O}_{2}\left(1 \mathrm{~min}^{-1}\right)$, carbon dioxide output $\left(\dot{V} \mathrm{CO}_{2}, 1 \mathrm{~min}^{-1}\right)$, and expired ventilation $\left(\dot{V}_{\mathrm{E}}, 1 \mathrm{~min}^{-1}\right)$ were determined at the mouth by means of a breath-by-breath respiratory monitoring system (Vmax 29, SensorMedics, USA). The average values at the steady state of each workload, calculated on a time basis of $1 \mathrm{~min}$, were retained.

Heart rate $\left(f \mathrm{H}, \mathrm{min}^{-1}\right)$ was measured by electrocardiography (Elmed ETM 2000, Germany) and $\mathrm{SaO}_{2}$ by fingertip infrared oximetry (Ohmeda 2350 Finapres, USA). The subjects were instructed not to grip the cycle bar with the hand that carried the finger cuff. [Hb] $\left(\mathrm{g} \mathrm{l}^{-1}\right)$ was measured by a photometric technique (HemoCue, Sweden) on $10 \mu$ blood samples. Blood lactate concentration $\left([\mathrm{La}]_{\mathrm{b}}\right)$ was measured by an electroenzymatic method (Eppendorf EBIO 6666, Germany) on $20 \mu \mathrm{l}$ blood samples. Arterialised blood gas composition was measured by means of microelectrodes (280 Blood Gas System, Ciba Corning, USA) on $80 \mu \mathrm{l}$ blood samples. All blood samples were taken from an ear lobe which was previously made hyperhaemic by means of a vasodilating ointment in order to avoid underestimation of oxygen partial pressure values.

$\dot{Q}\left(1 \mathrm{~min}^{-1}\right)$ was measured by the one-step $\mathrm{CO}_{2}$ rebreathing method (Farhi et al. 1976). The $\mathrm{CO}_{2}$ fraction at the mouth immediately before and during the rebreathing manoeuvre was continuously analysed by means of a mass spectrometer (Balzers Prisma, Liechtenstein). Breathing volume and rebreathing frequency were selected so as to obtain an initial drop in alveolar $\mathrm{CO}_{2}$ pressure $\left(P_{\mathrm{ACO}}\right)$. The subjects were instructed to completely empty the rebreathing bag, or nearly so, at each inspiration. The beginning of rebreathing was controlled by an automatic system which had been previously described (Anchisi et al. 2001). Rebreathing was terminated by the operator within at most ten breaths, unless the $P_{\mathrm{ACO}}$ reached $55 \mathrm{mmHg}$, in which case the rebreathing procedure was stopped automatically by the system. The one-step $\mathrm{CO}_{2}$ rebreathing method measures the $\dot{Q}$ of the time period immediately preceding the rebreathing manoeuvre, if the $\mathrm{PCO}_{2}$ during rebreathing recovers to the initial steady state $P_{\mathrm{ACO}}$ in less than $10 \mathrm{~s}$ or at least within a circulation time (Matalon et al. 1982). Under these conditions, the acute beat-by-beat changes in $\dot{Q}$ induced by rebreathing do not affect the calculated steady-state $\dot{Q}$ values. Moreover, a rebreathing mixture containing $60 \%$ of $\mathrm{O}_{2}$ in $\mathrm{N}_{2}$ could be used also for the experiments in hypoxia. This allowed fulfilment of a precise gas matching at the alveolo-capillary level during the entire rebreathing manoeuvre, so that the assumption of a standard $\mathrm{CO}_{2}$ dissociation curve during rebreathing could be maintained (Farhi et al. 1976). Correction for changes in $[\mathrm{Hb}]$ was introduced in the computation algorithm. The method shows a close correspondence with the direct Fick method, despite a slight tendency to overestimate $\dot{Q}$ at rest (Ohlsson and Wranne 1986).

The stroke volume $(\mathrm{SV}, \mathrm{ml})$ was calculated as the ratio between $\dot{Q}$ and $f \mathrm{H}$. The $\mathrm{CaO}_{2},\left(\mathrm{ml} \mathrm{l}^{-1}\right)$ was ob- 
tained as the product of $[\mathrm{Hb}], \mathrm{SaO}_{2}$, and the physiological $\mathrm{O}_{2}$ binding coefficient of haemoglobin $\left(1.34 \mathrm{ml} \mathrm{g}^{-1}\right)$. The $\dot{Q} \mathrm{aO}_{2}$ was calculated as the product of $\dot{Q}$ times $\mathrm{CaO}_{2}$, and the $\dot{Q} \overline{\mathrm{v}} \mathrm{O}_{2}$ was calculated as the difference between $\dot{Q} \mathrm{aO}_{2}$ and $\dot{V} \mathrm{O}_{2}$. Mixed venous oxygen concentration $\left(C \bar{v} \mathrm{O}_{2}\right)$ was calculated as the ratio of $\dot{Q} \overline{\mathrm{v}} \mathrm{O}_{2}$ to $\dot{Q}$. The oxygen extraction coefficient $\left(\mathrm{O}_{2}\right.$ ext $)$ was calculated as the ratio of $\dot{V} \mathrm{O}_{2}$ to $\dot{Q} \mathrm{aO}_{2}$.

\section{Protocol}

Experiments were performed in normoxia (breathing ambient air) and in acute normobaric hypoxia $\left(\mathrm{FiO}_{2}=\right.$ 0.11 , corresponding to inspired oxygen partial pressures, $\mathrm{PiO}_{2}$, of $80 \mathrm{mmHg}$ ). In both conditions the subjects performed two incremental exercise tests, one without $\beta$ blockade (control condition, $C$ ) and one after having induced quasi-complete $\beta 1$-adrenergic blockade with metoprolol ( $\beta$-blockade, BB). Thus each subject participated in four experimental sessions which were carried out on different days. The experiments in normoxia always preceded those in hypoxia, and the experiments with $\beta$-blockade always followed the control tests.

In hypoxia, inspired air was administered from precision high-pressure gas cylinders via an 801 Douglas bag buffer. The inspired oxygen fraction, $\mathrm{FiO}_{2}$, was monitored on the inspiratory line close to the mouth. The gas flow from the cylinders was continuously adjusted to the subject's ventilation. Experiments in hypoxia were preceded by a 10 min period for gas store equilibration.

In the BB experiments, intravenous administration of metoprolol (Loprésor, Novartis, Switzerland), a selective inhibitor of $\beta 1$-adrenergic receptors, was performed prior to the incremental exercise test. After a first intravenous bolus of $7.5 \mathrm{mg}$, additional doses up to 30 $40 \mathrm{mg}$ were administered until a quasi-complete receptor blockade was achieved. This was suggested by a $10-15 \%$ reduction in basal $f \mathrm{H}$ and by more than $60 \%$ inhibition of isoprenaline-induced tachycardia (up to $0.15 \mu \mathrm{g} \mathrm{kg}^{-1}$ $\min ^{-1}$ ). The isoprenaline test was performed only on the first occasion, for the experiments in normoxia, when the appropriate metoprolol dosage for inducing quasicomplete receptor blockade was determined. The same dosage was then applied in all the subsequent tests.

In each of the four sessions, the investigated parameters were determined at rest and at the steady state of submaximal dynamic leg exercises on the cycle ergometer. The selected workloads were $50,100,150$, and $200 \mathrm{~W}$ and were administered in increasing order. The $200 \mathrm{~W}$ workload, however, was not performed in hypoxia because in some subjects it was sufficiently close to their maximal aerobic power to prevent the attainment of a metabolic steady state. The duration of each workload was 8 $11 \mathrm{~min}$. Successive workloads were separated by $5 \mathrm{~min}$ recovery intervals, during which blood sampling for $[\mathrm{La}]_{b}$ determinations were performed at 1,3 , and $5 \mathrm{~min} . \dot{V} \mathrm{O}_{2}$, $f \mathrm{H}$, and $\mathrm{SaO}_{2}$ were measured continuously throughout the entire protocol. The $\dot{V} \mathrm{O}_{2}$ monitoring, however, was inevitably interrupted during the rebreathing manoeuvres.

At rest, as at each workload, three rebreathing procedures were performed, the first after 3 min from start and the others as soon as a clear respiratory steady state was re-established, but never before at least $2 \mathrm{~min}$ had elapsed from the end of the previous rebreathing. The return to a steady state was identified from the stability of breath-by-breath $\dot{V} \mathrm{O}_{2}$ values, beat-by-beat heart rate values, and continuous $\mathrm{SaO}_{2}$ recordings. The mean of the three $\dot{Q}$ measurements was retained as the $\dot{Q}$ value for that exercise level.

Table 1 Arterialised blood gas composition, $\mathrm{pH}$, lactate, and ventilatory parameters at rest and at steady-state exercise in normoxia and in hypoxia without (C) and with (BB) $\beta 1$-adrenergic blockade

\begin{tabular}{|c|c|c|c|c|c|c|c|c|c|c|c|c|c|c|}
\hline \multirow{2}{*}{$\begin{array}{l}\text { Power (W) } \\
0\end{array}$} & \multicolumn{2}{|l|}{ Condition } & \multicolumn{2}{|c|}{$\begin{array}{l}\text { Lactate } \\
(\mathrm{mM})\end{array}$} & & \multicolumn{2}{|c|}{$\begin{array}{l}\mathrm{PaCO}_{2} \\
(\mathrm{mmHg})\end{array}$} & \multicolumn{2}{|c|}{$\begin{array}{l}\mathrm{PaO}_{2} \\
(\mathrm{mmHg})\end{array}$} & \multicolumn{2}{|c|}{$\begin{array}{l}\dot{V} \mathrm{CO}_{2} \\
\left(1 \mathrm{~min}^{-1}\right)\end{array}$} & \multicolumn{2}{|c|}{$\dot{V}_{\mathrm{E}}\left(1 \mathrm{~min}^{-1}\right)$} \\
\hline & Normoxia & $\mathrm{C}$ & 1.61 & 0.60 & 7.39 & 0.02 & 41.9 & 2.0 & 76.9 & 2.8 & 0.27 & 0.06 & 10.62 & 3.15 \\
\hline & \multirow[t]{2}{*}{ Hypoxia } & $\mathrm{C}$ & 2.27 & 0.88 & 7.43 & 0.02 & 32.2 & 2.8 & 38.1 & 1.5 & 0.46 & 0.06 & 18.80 & 3.96 \\
\hline & & BB & 1.38 & 0.26 & 7.42 & 0.03 & 34.2 & 2.2 & 39.5 & 2.7 & 0.43 & 0.04 & 17.72 & 4.30 \\
\hline \multirow[t]{2}{*}{50} & \multirow[t]{2}{*}{ Normoxia } & C & 1.27 & 0.35 & 7.39 & 0.03 & 39.9 & 2.5 & 76.1 & 6.2 & 0.81 & 0.06 & 24.15 & 2.66 \\
\hline & & BB & 1.49 & 0.30 & 7.37 & 0.01 & 42.1 & 3.1 & 72.9 & 2.8 & 0.80 & 0.07 & 25.25 & 4.80 \\
\hline \multirow[t]{4}{*}{100} & \multirow[t]{2}{*}{ Normoxia } & C & 1.53 & 0.46 & 7.39 & 0.02 & 40.5 & 1.8 & 78.6 & 1.6 & 1.45 & 0.13 & 38.79 & 5.47 \\
\hline & & BB & 1.62 & 0.25 & 7.37 & 0.02 & 41.4 & 2.8 & 76.4 & 4.0 & 1.35 & 0.18 & 38.14 & 6.52 \\
\hline & \multirow[t]{2}{*}{ Hypoxia } & C & 3.17 & 0.77 & 7.42 & 0.03 & 30.2 & 2.6 & 36.2 & 5.8 & 1.73 & 0.17 & 55.39 & 7.72 \\
\hline & & BB & 2.41 & 0.72 & 7.41 & 0.05 & 32.3 & 3.1 & 34.9 & 5.4 & 1.70 & 0.21 & 54.62 & 9.05 \\
\hline \multirow[t]{2}{*}{150} & \multirow[t]{2}{*}{ Normoxia } & $\mathrm{C}$ & 2.26 & 0.90 & 7.38 & 0.03 & 38.5 & 1.4 & 78.7 & 3.9 & 2.09 & 0.23 & 55.53 & 7.74 \\
\hline & & BB & 2.44 & 0.75 & 7.36 & 0.02 & 39.6 & 2.5 & 75.5 & 4.7 & 1.99 & 0.14 & 52.97 & 6.43 \\
\hline
\end{tabular}

$\mathrm{PaCO}_{2}$, arterialised blood carbon dioxide partial pressure; $\mathrm{PaO}_{2}$, arterialised blood oxygen partial pressure; $\dot{V} \mathrm{CO}_{2}$, carbon dioxide output; $\dot{V} \mathrm{E}$, expired ventilation. Data are given as mean (bold character) $\pm \mathrm{SD}$ (normal character on immediate right) 
[Hb] was determined before each rebreathing procedure. Steady-state $\dot{V} \mathrm{O}_{2}, \dot{V} \mathrm{CO}_{2}$, and $\dot{V} \mathrm{E}$ were averaged in the minute that preceded the performance of the last rebreathing. The average $\mathrm{SaO}_{2}$ and $f \mathrm{H}$ values over the same period were retained as the steady-state $\mathrm{SaO}_{2}$ and $f \mathrm{H}$. Arterialised blood gas composition was determined before the second rebreathing (Table 1).

\section{Statistics}

Data are given as mean and standard deviation. The ANOVA was used to assess the differences for each measured and calculated parameter between the four tested conditions (normoxia and hypoxia, with and without $\mathrm{BB}$ ) at the investigated work rates. A post hoc Bonferroni test was used to determine differences between pairs. Regression equations were computed by the least square method. Differences between regression lines were assessed by ANOVA (Kleinbaum et al. 1988). A normal distribution of errors was assumed. The results were considered significant if $p<0.05$.

\section{Results}

\section{Respiratory variables}

$\dot{V} \mathrm{O}_{2}$ was a linear function of mechanical power $(\dot{w})$. Since this relation was the same in all the investigated conditions, an overall relationship was calculated described by the following equation: $\dot{V} \mathrm{O}_{2}=$ $0.0122 \dot{w}+0.396, n=108, r=0.989$. From the slope of this line an average mechanical efficiency of exercise of 0.235 was computed. The increase in $\dot{V} \mathrm{CO}_{2}$ with $\dot{w}$ was parallel to that in $\dot{V} \mathrm{O}_{2}$. The gas exchange ratio was never higher than 1, except at $150 \mathrm{~W}$ in hypoxia.

Respiratory and metabolic data are reported in Table 1. In $\mathrm{C}$, both $\mathrm{O}_{2}$ and $\mathrm{CO}_{2}$ partial pressures $\left(\mathrm{PaO}_{2}\right.$ and $\mathrm{PaCO}_{2}$, respectively) were lower in hypoxia than in normoxia. In both conditions, $\mathrm{BB}$ did not induce significant differences in $\mathrm{PaO}_{2}$ and $\mathrm{PaCO}_{2}$ with respect to C. Arterialised blood $\mathrm{pH}$ was higher in hypoxia than in normoxia and was unaffected by BB. The ensemble of this data indicate occurrence of hyperventilation in hypoxia as demonstrated also by the significantly higher $\dot{V} \mathrm{E}$ values at each workload in hypoxia than in normoxia. $[\mathrm{La}]_{\mathrm{b}}$ was higher in hypoxia than in normoxia and was unaffected by BB. The highest $[\mathrm{La}]_{\mathrm{b}}$ values were observed at $150 \mathrm{~W}$ in hypoxia $(5.64 \pm 1.84$ and $5.36 \pm 2.22 \mathrm{mM}$ in $\mathrm{C}$ and $\mathrm{BB}$, respectively).

Cardiovascular oxygen transport in the control condition

The values observed for the cardiovascular oxygen transport parameters at rest and at the steady state of each workload in normoxia and in hypoxia are summarised in Table 2. $f \mathrm{H}, \mathrm{SV}, \dot{Q}$ and $\dot{Q} \mathrm{aO}_{2}$ increased significantly at exercise in both normoxia and in hypoxia. $f \mathrm{H}$ was systematically and significantly higher in hypoxia than in normoxia at each workload.

In the following figures, the values describing the relations between variables observed in $\mathrm{C}$ are reported as

Table 2 Cardiovascular oxygen transport at rest and during exercise in normoxia and hypoxia without (C) and with (BB) $\beta 1$-adrenergic blockade

\begin{tabular}{|c|c|c|c|c|c|c|c|c|c|c|c|c|c|c|c|c|c|c|c|c|c|}
\hline \multicolumn{2}{|c|}{ Power(W) } & \multicolumn{2}{|c|}{$\underset{\left(1 \min ^{-1}\right)}{\dot{Q}}$} & \multicolumn{2}{|c|}{$\begin{array}{l}f \mathrm{H} \\
\left(\mathrm{min}^{-1}\right)\end{array}$} & \multicolumn{2}{|c|}{$\mathrm{SV}(\mathrm{ml})$} & \multicolumn{2}{|l|}{$\mathrm{SaO}_{2}$} & \multicolumn{2}{|c|}{$\mathrm{CaO}_{2}$} & \multicolumn{2}{|c|}{$\begin{array}{l}\dot{V} \mathrm{O}_{2} \\
\left(1 \min ^{-1}\right)\end{array}$} & \multicolumn{2}{|c|}{$\frac{\dot{Q} \mathrm{aO}_{2}}{\left(1 \mathrm{~min}^{-1}\right)}$} & \multicolumn{2}{|c|}{$\mathrm{O}_{2} \mathrm{Ext}$} & \multicolumn{2}{|c|}{$\begin{array}{l}\dot{Q} \mathrm{VO}_{2} \\
\left(1 \mathrm{~min}^{-1}\right)\end{array}$} & \multicolumn{2}{|c|}{$\begin{array}{l}\mathrm{CvO}_{2} \\
\left(1 \mathrm{~min}^{-1}\right)\end{array}$} \\
\hline \multicolumn{22}{|c|}{ Normoxia } \\
\hline 0 & BB & 7.8 & 1.4 & 63 & 9 & 125 & 30 & 0.97 & 0.00 & 206 & 18 & 0.33 & 0.04 & 1.59 & 0.25 & 0.21 & 0.05 & 1.26 & 0.25 & 162 & 20 \\
\hline \multirow[t]{2}{*}{50} & $\mathrm{C}$ & 11.2 & 2.2 & 93 & 5 & 120 & 19 & 0.97 & 0.02 & 216 & 11 & 0.93 & 0.10 & 2.42 & 0.47 & 0.39 & 0.05 & 1.49 & 0.40 & 131 & 13 \\
\hline & BB & 11.6 & 1.1 & 78 & 4 & 150 & 16 & 0.97 & 0.02 & 214 & 18 & 0.92 & 0.14 & 2.50 & 0.37 & 0.38 & 0.11 & 1.58 & 0.45 & 134 & 30 \\
\hline 150 & BB & 15.4 & 1.7 & 101 & 7 & 153 & 26 & 0.96 & 0.01 & 217 & 16 & 2.03 & 0.12 & 3.32 & 0.27 & 0.61 & 0.05 & 1.29 & 0.26 & 83 & 12 \\
\hline \multirow[t]{2}{*}{200} & $\mathrm{C}$ & 19.9 & 1.7 & 153 & 11 & 131 & 18 & 0.96 & 0.01 & 227 & 14 & 2.90 & 0.28 & 4.52 & 0.52 & 0.65 & 0.08 & 1.62 & 0.52 & 81 & 19 \\
\hline & BB & 17.4 & 2.1 & 116 & 8 & 152 & 27 & 0.96 & 0.01 & 223 & 28 & 2.73 & 0.16 & 3.85 & 0.46 & 0.71 & 0.06 & 1.12 & 0.36 & 64 & 17 \\
\hline \multicolumn{22}{|c|}{ Hyрохіа } \\
\hline . & C & 10.6 & 3.1 & 83 & 11 & 127 & 33 & 0.79 & 0.03 & 178 & 10 & 0.45 & 0.08 & 1.87 & 0.50 & 0.26 & 0.08 & 1.41 & 0.49 & 132 & 13 \\
\hline \multirow[t]{2}{*}{150} & $\mathrm{C}$ & 23.3 & 1.5 & 156 & 11 & 150 & 9 & 0.64 & 0.04 & 147 & 8 & 2.48 & 0.25 & 3.43 & 0.19 & 0.73 & 0.08 & 0.95 & 0.31 & 41 & 13 \\
\hline & BB & 22.1 & 2.9 & 117 & 6 & 191 & 31 & 0.67 & 0.05 & 155 & 17 & 2.32 & 0.18 & 3.44 & 0.66 & 0.69 & 0.15 & 1.12 & 0.77 & 48 & 26 \\
\hline
\end{tabular}

$\dot{Q}$, cardiac output; $f \mathrm{H}$, heart rate; $\mathrm{SV}$, stroke volume; $\mathrm{SaO}_{2}$, arterial $\mathrm{O}_{2}$ saturation; $C \mathrm{aO}_{2}$, arterialised $\mathrm{O}_{2}$ concentration; $\dot{V} \mathrm{O}_{2}, \mathrm{O}_{2}$ consumption; $Q \mathrm{aO}{ }_{2}, \mathrm{O}_{2}$ delivery; $\mathrm{O}_{2}$ ext, $\mathrm{O}_{2}$ extraction coefficient; $Q \overline{\mathrm{v}} \mathrm{O}_{2}, \mathrm{O}_{2}$ return; $C \overline{\mathrm{v}} \mathrm{O}_{2}$, mixed venous $\mathrm{O}_{2}$ concentration. Data are given as mean (bold character) \pm S.D. (normal character on immediate right) 
Fig. 1 Cardiac output as a function of heart rate. Each dot represents the mean value observed at a given power in each experimental condition. Regression lines were calculated on the individual values for each investigated condition. Regression equations for $\mathrm{C}$ were: $y=0.162 x-3.95$ in normoxia and $y=0.169$ $x-3.23$ in hypoxia. Regression equations for $\mathrm{BB}$ were:

$y=0.179 x-2.90$ in normoxia and $y=0.260 x-8.48$ in hypoxia. Thin lines are isopleths for stroke volume

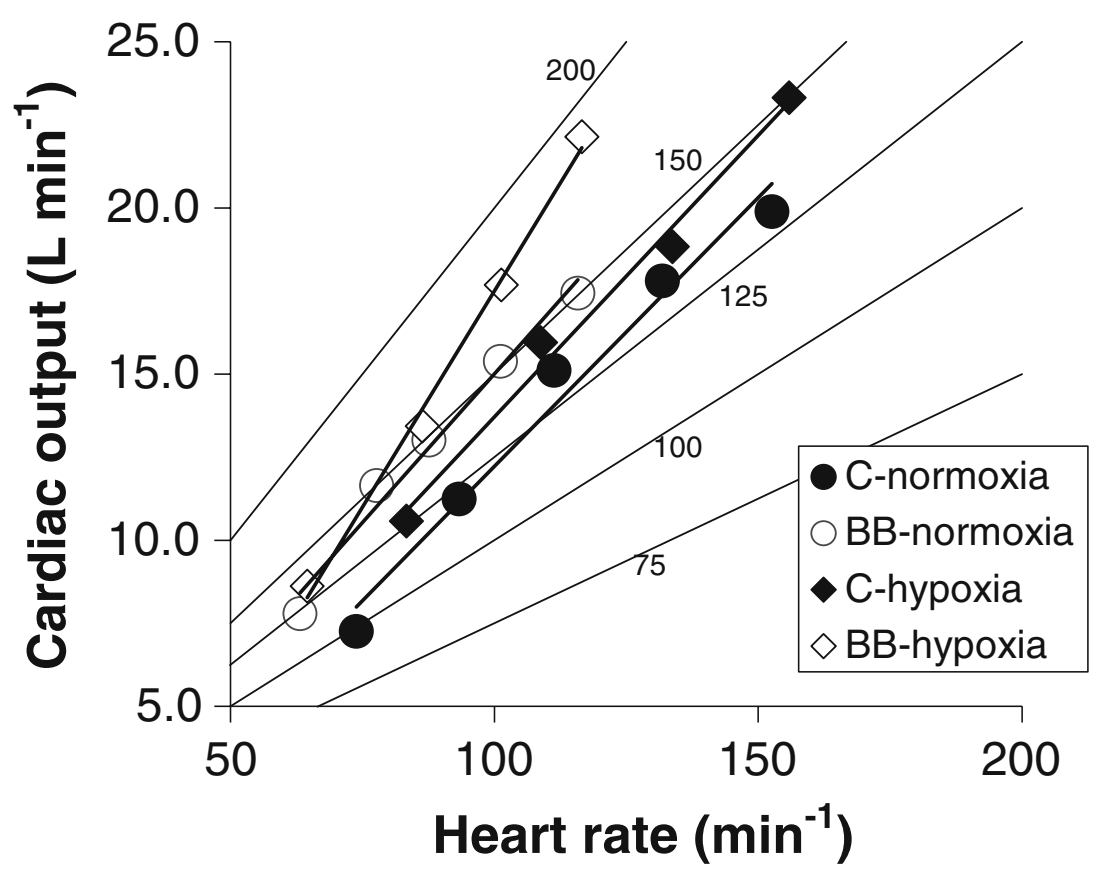

filled symbols (filled circle for normoxia, filled diamond for hypoxia).

The relationships between $\dot{Q}$ and $f \mathrm{H}$ are shown in Fig. 1. SV isopleths are also reported in the same figure. The regression lines did not differ significantly between them.

The relationships between $\dot{Q}$ and $\dot{V} \mathrm{O}_{2}$ are shown in Fig. 2. Isopleths for the arterial-venous $\mathrm{O}_{2}$ difference are also reported in the same figure. The regression line in hypoxia had a significantly steeper slope than in normoxia, so that, at each workload, $\dot{Q}$ was significantly higher in hypoxia than in normoxia. As $\dot{V} \mathrm{O}_{2}$ at each workload was the same, this finding was accompanied by correspondingly lower arterial-venous $\mathrm{O}_{2}$ differences in hypoxia than in normoxia.

$\mathrm{SaO}_{2}$ and $\mathrm{CaO}_{2}$ were lower in hypoxia than in normoxia. In hypoxia, they also decreased with increasing workload. As a result of this, and despite the lower arterial-venous $\mathrm{O}_{2}$ differences in hypoxia, the $\mathrm{O}_{2}$ extraction coefficient was greater in hypoxia than in normoxia (see Table 1).

The relationships between $\dot{Q} \mathrm{aO}_{2}$ and $\dot{V} \mathrm{O}_{2}$ are shown in Fig. 3. The regression line for normoxia had a slope significantly equal to 1 . This means that in normoxia the difference between $\dot{Q} \mathrm{aO}_{2}$ and $\dot{V} \mathrm{O}_{2}$ (equal to $\dot{Q} \overline{\mathrm{v}} \mathrm{O}_{2}$ ) did not change with increasing workload. In hypoxia the
Fig. 2 Cardiac output as a function of oxygen consumption. Each dot represents the mean value observed at a given power in each experimental condition. Regression lines were calculated on the individual values for each investigated condition. Regression equations for $\mathrm{C}$ were: $y=4.95 x+6.43$ in normoxia and $y=6.22$ $x+8.13$ in hypoxia.

Regression equations for BB were: $y=3.88 x+7.26$ in normoxia and $y=7.18$ $x+5.60$ in hypoxia. Thin lines are isopleths for arterial-venous oxygen difference

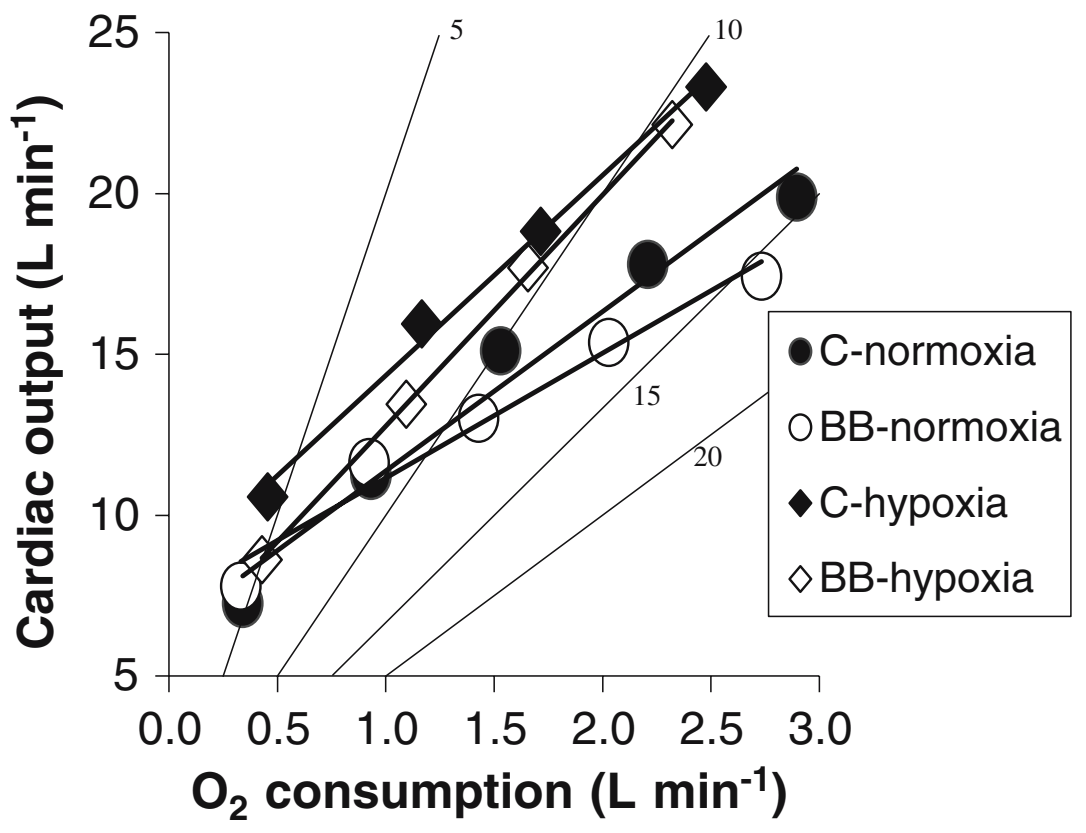


Fig. 3 Arterial oxygen flow as a function of oxygen represents the mean value each experimental condition. Regression lines were calculated on the individual values for each investigated condition. Regression equations for $\mathrm{C}$ normoxia and $y=0.74$ $x+1.56$ in hypoxia. Regression equations for $\mathrm{BB}$ were: $y=0.90 x+1.44$ in normoxia and $y=1.04$ $x+0.98$ in hypoxia. The thin line is the identity line consumption. Each dot observed at a given power in were: $y=1.04 x+1.57$ in

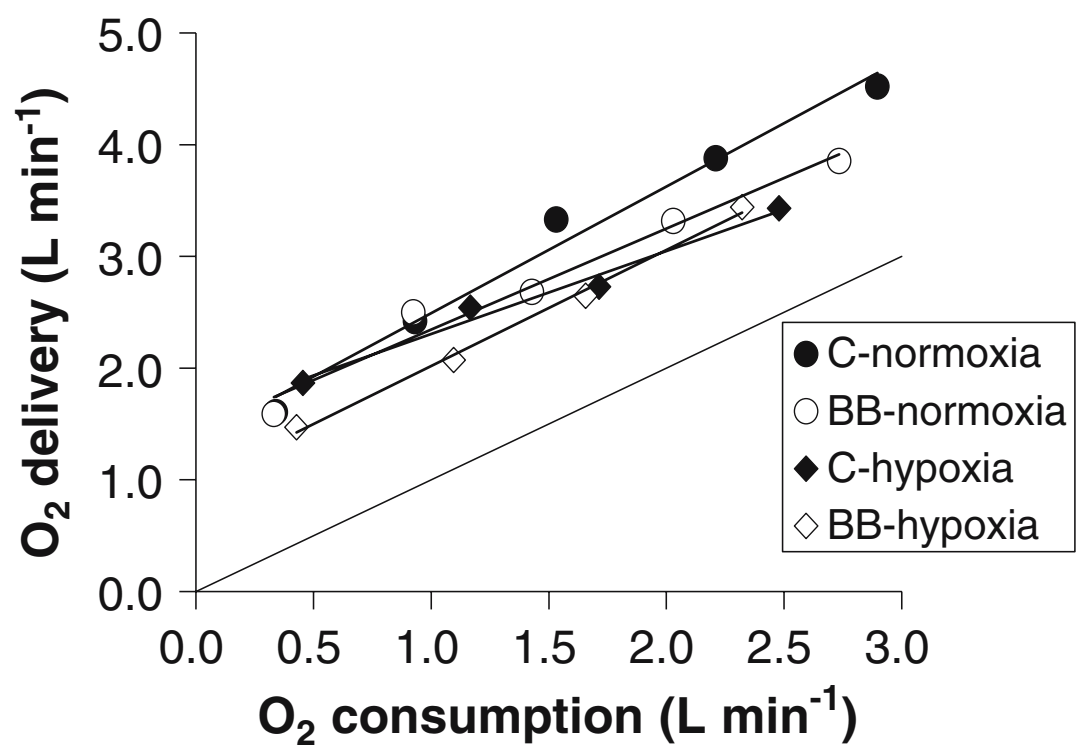

slope of the $\dot{Q} \mathrm{aO}_{2}$ vs $\dot{V} \mathrm{O}_{2}$ relationship (0.742) was significantly lower than 1 . This means that in hypoxia $\dot{Q} \overline{\mathrm{v}} \mathrm{O}_{2}$ decreased as a function of workload. As a consequence, in hypoxia, the $\dot{Q} \overline{\mathrm{v}} \mathrm{O}_{2}$ values at 100 and $150 \mathrm{~W}$ were significantly lower than the corresponding values in normoxia. The resting $\dot{Q} \overline{\mathrm{v}} \mathrm{O}_{2}$ value in normoxia, not included in the regression analysis, was significantly lower than the corresponding invariant values at exercise. In hypoxia the resting $\dot{Q} \overline{\mathrm{v}} \mathrm{O}_{2}$ value did not differ significantly from the corresponding value in normoxia. However, the $\dot{Q} \overline{\mathrm{v}} \mathrm{O}_{2}$ values at 100 and $150 \mathrm{~W}$ in $\mathrm{C}$ were significantly lower than the corresponding values in normoxia.

The effects of $\mathrm{BB}$ on cardiovascular oxygen transport

The values observed for the cardiovascular oxygen transport parameters at rest and at the steady state of each workload in normoxia and in hypoxia under $\mathrm{BB}$ are also shown in Table 2. As in C, $f \mathrm{H}$, SV, $\dot{Q}$, and $\dot{Q} \mathrm{aO}_{2}$ increased significantly at exercise, both in normoxia and in hypoxia. At rest and at each workload, $f \mathrm{H}$ was systematically and significantly decreased by $\mathrm{BB}$, both in normoxia and in hypoxia. The lower $f \mathrm{H}$ at any given $\dot{V} \mathrm{O}_{2}$ implied a significant increase in the oxygen pulse in $\mathrm{BB}$.

The effects of $\mathrm{BB}$ on the investigated parameters and on the relations between the analysed variables are reported in the same figures as for $\mathrm{C}$, by presenting the corresponding values as open symbols (open circle for normoxia, open diamond for hypoxia).

The relationships between $Q$ and $f \mathrm{H}$ under $\mathrm{BB}$ are combined in Fig. 1. The regression line in hypoxia had a significantly higher slope and a lower $y$-intercept than the corresponding line in normoxia. Thus, significantly higher $\dot{Q}$ values were found at each $f \mathrm{H}$ level under BB in
Fig. 4 Oxygen flow in mixed venous blood as a function of arterial oxygen saturation. Each symbol represents the mean value observed at a given power in each experimental condition. Regression lines were calculated on the individual values for the control condition and under $\beta 1$ adrenergic blockade. The linear relationship for $\mathrm{C}$, with the exclusion of the resting normoxic value, was described by $y=1.78 x-0.06$ and $r=0.904$. The corresponding relationship for $\mathrm{BB}$ was $y=0.92 x+0.40$ and $r=0.736$

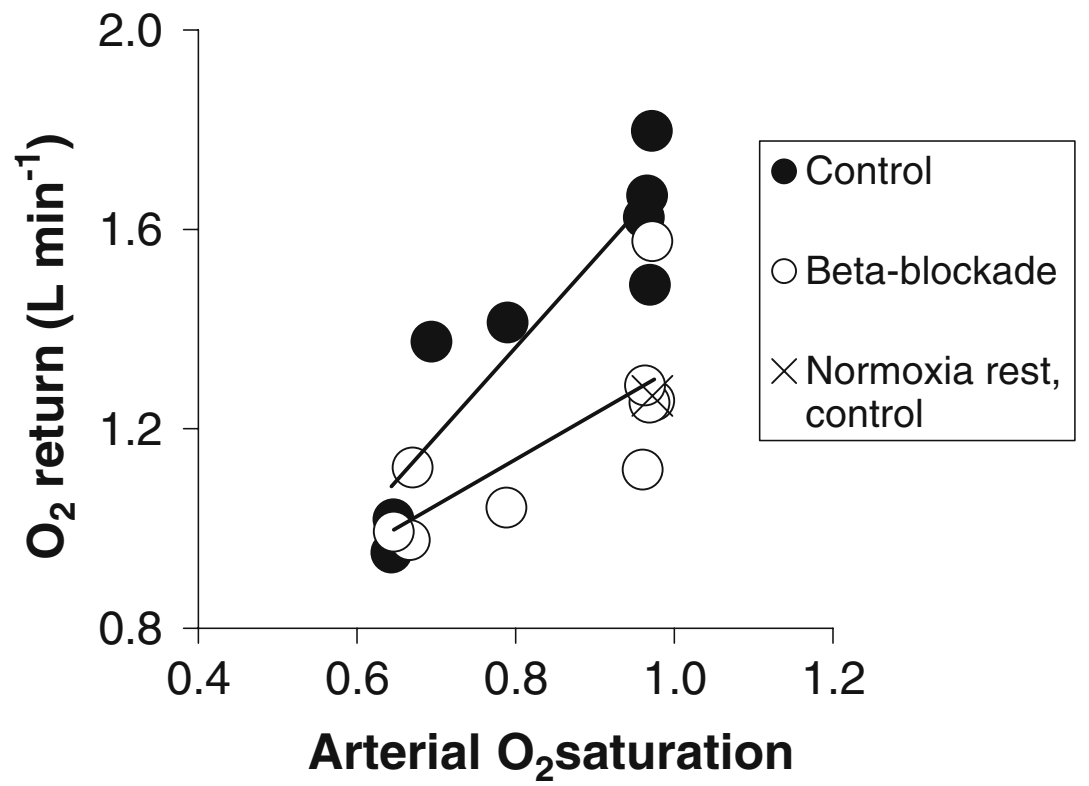


Fig. 5 Oxygen flow in mixed venous blood as a function of oxygen extraction coefficient. Each symbol represents the mean value observed at a given power in the four experimental conditions. The regression line, calculated on the individual values, was $y=-0.40 x+1.49$ and $n=18 ; r=0.268$; $0.05<p<0.1$

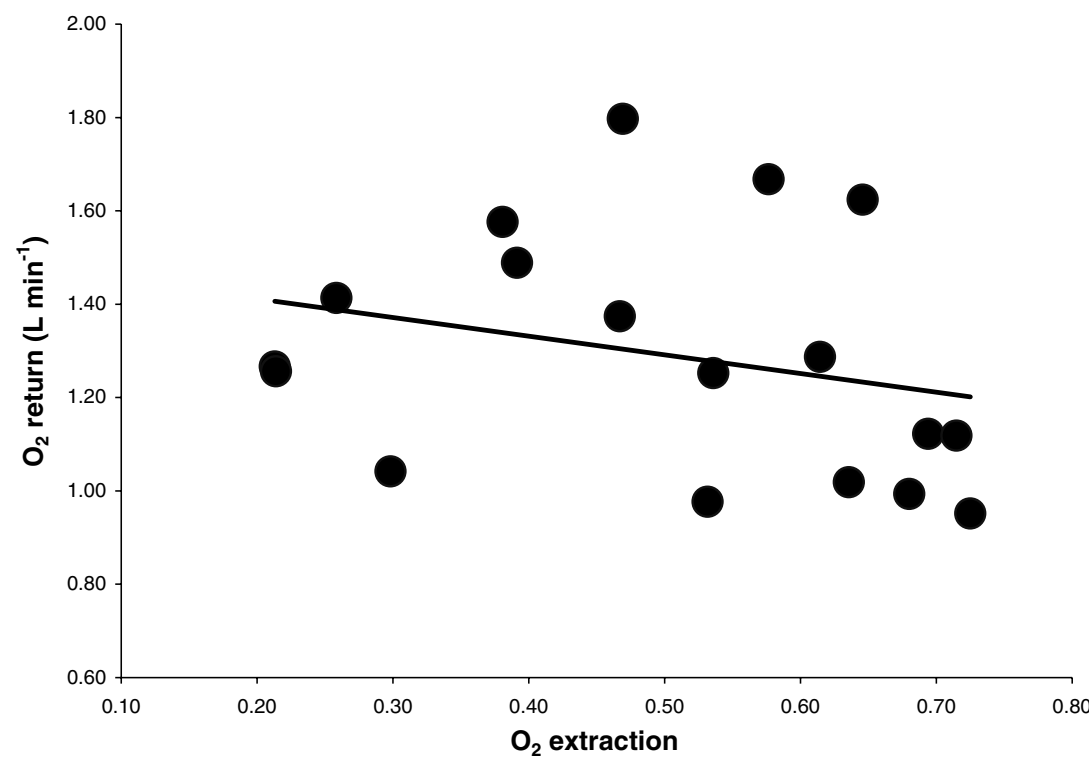

hypoxia than in normoxia as a consequence of increased $\mathrm{SV}$. With respect to $\mathrm{C}, \mathrm{BB}$ appeared to increase the slope of the $Q$ vs $f \mathrm{H}$ line in hypoxia, though not in normoxia. Significantly higher SV values were observed under BB than in $\mathrm{C}$ in both normoxia and hypoxia.

The relationships between $\dot{Q}$ and $V \mathrm{O}_{2}$ are combined in Fig. 2. The slope of the regression line in hypoxia was significantly higher than in normoxia. As $\dot{V} \mathrm{O}_{2}$ at each workload was the same, this finding implied correspondingly lower arterial-venous $\mathrm{O}_{2}$ differences in hypoxia than in normoxia also under BB. BB did not change these slopes significantly with respect to those of the corresponding lines in C. In normoxia, $\dot{Q}$ was significantly decreased by $\mathrm{BB}$ at $100 \mathrm{~W}$ exercise and above. In hypoxia, the same was the case at rest and at $50 \mathrm{~W}$ (Table 2).

As in $\mathrm{C}, \mathrm{SaO}_{2}$ and $\mathrm{CaO}_{2}$ were lower in hypoxia than in normoxia. In hypoxia they also decreased with increasing workload. In both conditions the values observed under BB were not significantly different from those found in C.

The relationships between $\dot{Q} \mathrm{aO}_{2}$ and $\dot{V} \mathrm{O}_{2}$ are combined in Fig. 3. The slope of the linear regression in normoxia did not differ significantly from that in C. However, the slope of the linear regression in hypoxia was significantly higher than that in C. None of the two slopes under BB was significantly different from 1, indicating invariant $\dot{Q} \overline{\mathrm{v}} \mathrm{O}_{2}$ at exercise under BB both in normoxia and in hypoxia. Coherently, in normoxia, $\dot{Q} \overline{\mathrm{v}} \mathrm{O}_{2}$ was significantly decreased with respect to the corresponding values in $\mathrm{C}$ for exercise levels upwards from $100 \mathrm{~W}$, but was unchanged at rest. In hypoxia $\dot{Q} \overline{\mathrm{v}} \mathrm{O}_{2}$ was significantly decreased with respect to $\mathrm{C}$ at rest and at $50 \mathrm{~W}$, but was unchanged at 100 and $150 \mathrm{~W}$.

Oxygen return, arterial oxygen saturation, and oxygen extraction

The $\dot{Q} \overline{\mathrm{v}} \mathrm{O}_{2}$ decrease as a function of workload in hypoxia paralleled an analogous decrease in $\mathrm{SaO}_{2} \cdot \dot{Q} \overline{\mathrm{v}} \mathrm{O}_{2}$ is shown as a function of $\mathrm{SaO}_{2}$ in Fig. 4. Two distinct linear relationships were observed: one for $\mathrm{C}$ and the other for BB. The line for C, calculated with the exclusion of the resting value in normoxia, had a significantly higher slope than the line for BB. The two lines converged onto the extreme hypoxic values. The resting control value in normoxia lied on the $\mathrm{BB}$ line.

The $\dot{Q} \overline{\mathrm{v}} \mathrm{O}_{2}$ variations as a function of $\mathrm{SaO}_{2}$, or as a function of the workload in hypoxia, were not a consequence of increased tissue oxygen extraction. Indeed the relationship between $\dot{Q} \overline{\mathrm{v}} \mathrm{O}_{2}$ and oxygen extraction coefficient was very weak (see Fig. 5).

\section{Discussion}

The results of the present study are in agreement with the tested hypothesis, as this study showed that selective blockade of $\beta 1$-adrenergic receptors decreased $\dot{Q} \mathrm{aO}_{2}$ and $\dot{Q} \overline{\mathrm{v}} \mathrm{O}_{2}$ significantly during exercise in normoxia as well as during rest and light exercise in hypoxia. These effects were a consequence of the reduction in $\dot{Q}$ that resulted from the inability to fully compensate for the BB-induced drop in $f \mathrm{H}$ through an increase in SV. It followed from this that BB altered the relationship between $\dot{Q} \overline{\mathrm{v}} \mathrm{O}_{2}$ and $\mathrm{SaO}_{2}$ whose slope was significantly reduced.

The results obtained in normoxia and in hypoxia in $\mathrm{C}$ compare well with those from previous studies. The linear relationship between $\dot{Q} \overline{\mathrm{v}} \mathrm{O}_{2}$ and $\mathrm{SaO}_{2}$, in C (see Fig. 4) did not differ from previously reported studies (Anchisi et al. 2001). The $\dot{Q} \overline{\mathrm{v}} \mathrm{O}_{2}$ value observed at rest in normoxia, a condition generally considered to be characterised by elevated vagal stimulation, lied exactly on the $\dot{Q} \overline{\mathrm{v}} \mathrm{O}_{2}$ vs $\mathrm{SaO}_{2}$ line for BB.

Heart rate, stroke volume, and cardiac output

The decrease in $f \mathrm{H}$ was observed in all studies with $\beta$ adrenergic blockade, and is generally attributed to the 
suppression of sympathetic control of the heart. The reduction of $f \mathrm{H}$ increases the time of diastole and therefore the telediastolic volume of the ventricle. Although $\beta 1$-adrenergic blockade has, if any, a negative inotropic effect (Matsuzaki et al. 1984), a higher telediastolic volume should result in a higher force of contraction by the Frank-Starling mechanism, leading to an increase in SV compensating for the reduced $f \mathrm{H}$. This was found in the present study, both in normoxia and in hypoxia, as well as in several other studies (Joyner et al. 1986; Kelbaek and Godtfredsen 1991; Pawelczyk et al. 1992; Vanhees et al. 2000).

SV increase, however, did not fully compensate for the decrease in $f \mathrm{H}$. This lack of compensation in normoxia implied significantly lower $\dot{Q}$ values under BB than in C at $100 \mathrm{~W}$ and above. In hypoxia, as previously reported (Stenberg et al. 1966; Hartley et al. 1973; Roca et al. 1989), higher $\dot{Q}$ values than in normoxia were observed at any metabolic level. BB led to a reduction of $\dot{Q}$ at any given workload because also in hypoxia the increase in $\mathrm{SV}$ was insufficient to compensate for the decrease in $f \mathrm{H}$. These $\dot{Q}$ values under BB were nevertheless still higher than those observed in normoxia in $\mathrm{C}$. This means that the $\dot{Q}$ increase in acute hypoxia is only partially due to an increased sympathetic outflow to the heart. In spite of this, $\dot{Q}$ was the same in BB as in C at rest and at $50 \mathrm{~W}$ in normoxia. These are the two conditions under which sympathetic activation can be assumed to be at its minimum and vagal activation at its maximum (Yamamoto et al. 1996). Thus, the bradycardic effect of specific $\beta 1$ adrenergic blockade was minimal, because sympathetic inhibition was already taking place, so that the SV increase could effectively maintain $\dot{Q}$.

\section{Oxygen delivery and oxygen return}

In normoxia, the increase in $\dot{Q}_{\mathrm{aO}}$ with power paralleled the increase in $\dot{V} \mathrm{O}_{2}$. Thus, $\dot{Q} \overline{\mathrm{v}} \mathrm{O}_{2}$ did not vary as a function of exercise intensity, in agreement with previous findings (Ferretti et al. 1992). At rest, however, $\dot{Q} \overline{\mathrm{v}} \mathrm{O}_{2}$ was definitely lower than at any exercise level. This agrees with the notion that resting humans are under predominant vagal control, whereas the sympathetic outflow to the heart is essentially inhibited. Under $\mathrm{BB}$, because of unchanged $\mathrm{CaO}_{2}$, diminutions of $\dot{Q}_{\mathrm{aO}}$ parallel to the changes in $\dot{Q}$ were observed. Since at each workload $\dot{V} \mathrm{O}_{2}$ was the same in $\mathrm{BB}$ as in $\mathrm{C}$, lower $\dot{\mathrm{aO}}_{2}$ values implied a $\dot{Q} \overline{\mathrm{v}} \mathrm{O}_{2}$ reduction with respect to $\mathrm{C}$. Consistently, no reductions of $\dot{Q} \mathrm{aO}_{2}$ and $\dot{Q} \overline{\mathrm{v}} \mathrm{O}_{2}$ were found at rest, where BB-induced bradycardia was minimal.

In hypoxia, with respect to normoxia, the association of higher $\dot{Q}$ values with lower $\mathrm{CaO}_{2}$ levels was such as to generate lesser $\dot{Q} \mathrm{aO}_{2}$ increases at the various workloads. As a consequence, the linear relationship between $\dot{Q} \mathrm{aO}_{2}$ and $\dot{V} \mathrm{O}_{2}$ had a slope significantly lower than 1. This implied a decrease in $\dot{Q} \overline{\mathrm{v}} \mathrm{O}_{2}$ with exercise intensity. Such a decrease was parallel to that in $\mathrm{SaO}_{2}$ as shown also in previous studies (Koskolou et al. 1997a; Anchisi et al.
2001). Under BB, because $\mathrm{CaO}_{2}$ was unchanged, drops in $\dot{Q} \mathrm{aO}_{2}$ parallel to the changes in $\dot{Q}$ were again observed. As a consequence, $\dot{Q} \overline{\mathrm{v}} \mathrm{O}_{2}$ was significantly lower in $\mathrm{BB}$ than in $\mathrm{C}$ at rest and $50 \mathrm{~W}$, but not at 100 and $150 \mathrm{~W}$ exercise.

The data combination discussed above resulted in two distinct relationships between $\dot{Q} \overline{\mathrm{v}} \mathrm{O}_{2}$ and $\mathrm{SaO}_{2}$. One line, similar to that previously reported (Anchisi et al. 2001), referred to all data obtained in C except for the resting value in normoxia: coherently with our conjecture, we propose that it describes a condition of predominant sympathetic control. The other, flatter, refers to all data obtained with $\beta 1$-adrenergic blockade plus the resting value in normoxia: it applies to conditions in which the sympathetic outflow to the heart is inhibited, either physiologically or pharmacologically, and the heart is under predominant vagal control.

The observation that $\mathrm{BB}$ failed to reduce $\dot{Q} \overline{\mathrm{v}} \mathrm{O}_{2}$ at intense exercise in hypoxia is in apparent contradiction with the above reasoning. Several factors may modulate the neural regulation of cardiovascular oxygen transport in deep hypoxia. Acute hypoxia was found to displace upward and rightward the baroreflex control of $f \mathrm{H}$ and increase muscle sympathetic nerve activity (Halliwill and Minson 2002). Baroreflex activity was not investigated in this study, but its investigation would be of great interest in future studies of oxygen transport during exercise. The potential role of peripheral chemoreceptors also cannot be neglected, as they act not only on ventilation but also on the cardiovascular system. Last but not the least, the loss of oxygen bound to haemoglobin may represent a strong stimulus (Anchisi et al. 2001; Gonzalez-Alonso et al. 2001, 2002) acting on the cardiovascular oxygen transport. This stimulus may lead to a marked overall sympathetic stimulation, mediated also by $\alpha$-adrenergic or $\beta 2$-adrenergic receptors, which would keep up $\dot{Q} \mathrm{aO}_{2}$ and $\dot{Q} \overline{\mathrm{v}} \mathrm{O}_{2}$, preventing them from reaching extremely low levels. However, since (1) metoprolol is a competitive blocker of $\beta 1$-adrenergic receptors, (2) circulating catecholamines increase at exercise and are higher in hypoxic than in normoxic exercise (Escourrou et al. 1984; Hughson et al. 1995), and (3) circulating catecholamines could not be measured in this study, one cannot disregard the hypothesis that incomplete $\beta 1$ adrenergic blockade might have occurred at the highest workloads in hypoxia because of very high catecholamine concentrations.

On the modulation of the oxygen transport system during exercise and hypoxia

The weak relationship between oxygen extraction and $\dot{Q} \overline{\mathrm{v}} \mathrm{O}_{2}$ (Fig. 5) demonstrates that $Q \overline{\mathrm{v}} \mathrm{O}_{2}$ is not a mere passive consequence of the Fick principle, simply reducing when tissues extract more oxygen as, for example, in hypoxia (see Table 2). In agreement with this is the observation that $\dot{Q} \overline{\mathrm{v}} \mathrm{O}_{2}$ is independent of the workload in normoxia, although oxygen extraction in- 
creases with the exercise intensity. At any given metabolic level $\dot{Q} \overline{\mathrm{v}} \mathrm{O}_{2}$ and $\dot{Q} \mathrm{aO}_{2}$ are the result of a complex homeostatic regulation, in which the changes in $\dot{Q}$, as determined by $f \mathrm{H}$ and SV modulation by the sympathetic and the vagal systems, play a role. In hypoxia $Q \overline{\mathrm{v}} \mathrm{O}_{2}$ is modulated also by the changes in $\mathrm{SaO}_{2}$ (Fig. 4). On the basis of this concept, the present results allow a general scheme of the changes to be proposed in the oxygen transport system in hypoxia and exercise. This scheme relies on the following notions:

1. There are two distinct relationships between $\dot{Q} \overline{\mathrm{v}} \mathrm{O}_{2}$ and $\mathrm{SaO}_{2}$, one describing a condition of predominant vagal control and the other a condition of predominant sympathetic control.

2. The latter line would be displaced upward with respect to the former.

3. Moving from the "vagal" to the "sympathetic" line and vice versa would imply resetting of the cardiovascular regulation.

The resting $\dot{Q} \overline{\mathrm{v}} \mathrm{O}_{2}$ value in normoxia lies on the "vagal" line and thus is unaffected by BB. During normoxic exercise vagal withdrawal occurs and sympathetic stimulation takes place so that the $\dot{Q} \overline{\mathrm{v}} \mathrm{O}_{2}$ values move up towards the "sympathetic" $\dot{Q} \overline{\mathrm{v}} \mathrm{O}_{2}$ vs $\mathrm{SaO}_{2}$ line. When sympathetic stimulation is withdrawn by $\beta 1$-adrenergic blockade, $\dot{Q} \overline{\mathrm{v}} \mathrm{O}_{2}$ is decreased towards the "vagal" line. The administration of hypoxia at rest - implying a decrease in $\mathrm{SaO}_{2}$, an increased sympathetic activity and perhaps a reduced vagal activity - moves $\dot{Q} \overline{\mathrm{v}} \mathrm{O}_{2}$ upward and leftward towards the "sympathetic" $Q \overline{\mathrm{v}} \mathrm{O}_{2}$ vs $\mathrm{SaO}_{2}$ line. During exercise in hypoxia, since the subjects operate on the steep portion of the oxygen equilibrium curve, $\mathrm{SaO}_{2}$ decreases with respect to the resting value and $\dot{Q} \overline{\mathrm{v}} \mathrm{O}_{2}$ moves down the "sympathetic" $\dot{Q} \overline{\mathrm{v}} \mathrm{O}_{2}$ vs the $\mathrm{SaO}_{2}$ line, becoming lower with increasing exercise intensity. For this reason the slope of the $\dot{Q} \mathrm{aO}_{2}$ vs $\dot{V} \mathrm{O}_{2}$ line in hypoxia turns out significantly lower than 1 .

In this context, we would have expected $\mathrm{BB}$ to reduce $\dot{Q} \overline{\mathrm{v}} \mathrm{O}_{2}$ also during intense exercise in hypoxia. This was not the case in this study. As discussed above, the lack of BB effects on $\dot{Q} \overline{\mathrm{v}} \mathrm{O}_{2}$ during exercise in hypoxia was explained either by the possible intervention of other, peripheral control mechanisms elicited by hypoxaemia or by incomplete BB during intense exercise in hypoxia.

In subjects acclimatised to altitude, a greater degree of sympathetic activation was found with respect to that observed at sea level (Perini et al. 1996). It has been recently demonstrated, however, that acclimatisation to altitude is associated with an increase in parasympathetic activity with respect to the condition of acute hypoxia, which accounts for the progressive reduction in $f \mathrm{H}$ with time at altitude (Boushel et al. 2001). This reduction in $f \mathrm{H}$, and thus in $Q$, compensates for the increase in $\mathrm{CaO}_{2}$ due to the higher haemoglobin concentration such that at any metabolic and $\mathrm{SaO}_{2}$ level, $\dot{Q} \mathrm{aO}_{2}$, and thus $\dot{Q} \overline{\mathrm{v}} \mathrm{O}_{2}$ are maintained unchanged and on the appropriate $\dot{Q} \overline{\mathrm{v}} \mathrm{O}_{2}$ vs $\mathrm{SaO}_{2}$ line. An analogous reduction in $f \mathrm{H}$ and thus in $\dot{Q}$, was observed during exercise in normoxia after induction of polycythaemia (Ferretti et al. 1992), the reverse being observed in acute anaemia (Koskolou et al. 1997b). It is tempting to propose such compensation to be mediated by a change in the sympatho-vagal balance. This would mean that, for any given $\mathrm{SaO}_{2}$ level, the degree of sympathetic activation is decreased and that of vagal activation is increased, the higher the haemoglobin concentration and thus $\mathrm{CaO}_{2}$. These changes may act not only on the heart, but also on muscle adrenergic receptors as anaemia is associated with an increase in muscle blood flow (Gonzalez-Alonso et al. 2001).

Acknowledgments This work was supported by Swiss National Science Foundation grants 32-49811.96 and 32-61780.00 to Guido Ferretti.

\section{References}

Anchisi S, Moia C, Ferretti G (2001) Oxygen delivery and oxygen return in humans exercising in acute normobaric hypoxia. Pflügers Arch 442:443-450

Boushel R, Calbet JA, Rådegran G, Sondergaard H, Wagner PD, Saltin B (2001) Parasympathetic neural activity accounts for the lowering of exercise heart rate at high altitude. Circulation 104:1785-1791

Escourrou P, Johnson DG, Rowell LB (1984) Hypoxemia increases plasma catecholamine concentrations in exercising humans. $\mathbf{J}$ Appl Physiol 57:1507-1511

Fagraeus L, Linnarsson D (1976) Autonomic origin of heart rate fluctuations at the onset of muscular exercise. J Appl Physiol 40:679-682

Farhi LE, Nesarajah MS, Olszowka AJ, Metildi LA, Ellis AK (1976) Cardiac output determination by a simple one step rebreathing technique. Respir Physiol 28:141-159

Ferretti G, Kayser B, Schena F, Turner DL, Hoppeler H (1992) Regulation of perfusive $\mathrm{O}_{2}$ transport during exercise in humans: effect of changes in haemoglobin concentration. J Physiol Lond 455:679-688

Gonzalez-Alonso J, Richardson RS, Saltin B (2001) Exercising skeletal muscle blood flow in humans responds to reduction in arterial oxyhaemoglobin, but not to altered free oxygen. J Physiol Lond 530:331-341

Gonzalez-Alonso J, Olsen DB, Saltin B (2002) Erythrocyte and the regulation of human skeletal muscle blood flow and oxygen delivery. Role of circulating ATP. Circ Res 91:1046-1055

Gullestad L, Dolva LO, Soyland E, Kjekshus J (1988) Difference between beta-1-selective and non-selective beta-blockade during continuous and intermittent exercise. Clin Physiol (Oxford) 8:487-499

Halliwill JR, Minson CT (2002) Effect of hypoxia on arterial baroreflex control of heart rate and muscle sympathetic nerve activity in humans. J Appl Physiol 93:857-864

Hartley LH, Vogel JA, Landowne L (1973) Central, femoral and brachial circulation during exercise in hypoxia. J Appl Physiol 34:87-90

Hughson RL, Green HJ, Sharratt MT (1995) Gas exchange, blood lactate, and plasma catecholamines during incremental exercise in hypoxia and normoxia. J Appl Physiol 79:1134-1141

Jilka SM, Joyner MJ, Nittolo JM, Kalis JK, Taylor JA, Lohman TG, Wilmore JH (1988) Maximal exercise responses to acute and chronic beta-adrenergic blockade in healthy male subjects. Med Sci Sports Exerc 20:570-573

Joyner MJ, Freund BJ, Jilka SM, Hetrick GA, Martinez E, Ewy GA, Wilmore JH (1986) Effects of $\beta$-blockade on exercise capacity of trained and untrained men: a hemodynamic comparison. J Appl Physiol 60:1429-1434 
Kaiser P, Tesch PA, Frisk-Holmberg M, Juhlin-Dannfelt A, Kaijser L (1986) Effect of beta 1-selective and non-selective beta-blockade on work capacity and muscle metabolism. Clin Physiol (Oxford) 6:197-207

Kalis JK, Freund BJ, Joyner MJ, Jilka SM, Nittolo J, Wilmore JH (1988) Effect of beta-blockade on the drift in $\mathrm{O}_{2}$ consumption during prolonged exercise. J Appl Physiol 64:753-758

Kelbaek H, Godtrfedsen J (1991) Effects of acute cardioselective and non-selective beta-adrenergic blockade on left-ventricular volumes and vascular resistance at rest and during exercise. Scand J Clin Lab Invest 51:161-166

Kleinbaum DG, Kupper LL, Muller KE (1988) Applied regression analysis and other multivariate methods. PWS-Kent, Boston

Koskolou MD, Calbet JAL, Rådegran G, Roach RC (1997a) Hypoxia and cardiovascular response to dynamic knee extensor exercise. Am J Physiol 272:H2655-H2663

Koskolou MD, Roach RC, Calbet JA, Rådegran G, Saltin B (1997b) Cardiovascular responses to dynamic exercise with acute anemia in humans. Am J Physiol 273:H1787-H1793

Lucy SD, Hughson RL, Kowalchuk JM, Paterson DH, Cunningham DA (2000) Body position and cardiac dynamic and chronotropic responses to steady-state isocapnic hypoxaemia in humans. Exp Physiol 85:227-238

Malliani A, Pagani M, Lombardi F, Cerutti S (1991) Cardiovascular neural regulation explored in the frequency domain. Circulation 84:482-492

Matalon S, Dashkoff N, Nesarajah MS, Klocke FJ, Farhi LE (1982) Effects of hyperventilation on pulmonary blood flow and recirculation time of humans. J Appl Physiol 52:1161-1166

Matsuzaki M, Patritti J, Tajimi T, Miller M, Kemper WS, Ross J Jr (1984) Effects of $\beta$-blockade on regional myocardial flow and function during exercise. Am J Physiol 247:H52-H60

Ohlsson J, Wranne B (1986) Non-invasive assessment of cardiac output and stroke volume in patients during exercise. Eur $\mathbf{J}$ Appl Physiol 55:538-544

Pawelczyk JA, Hanel B, Pawelczyk RA, Warberg J, Secher NH (1992) Leg vasoconstriction during dynamic exercise with reduced cardiac output. J Appl Physiol 73:1838-1846

Perini R, Milesi S, Biancardi L, Veicsteinas A (1996) Effects of high altitude acclimatization on heart rate variability in resting humans. Eur J Appl Physiol 73:521-528
Roach RC, Koskolou MD, Calbet JAL, Saltin B (1999) Arterial O content and tension in regulation of cardiac output and leg blood flow during exercise in humans. Am J Physiol 276:H438$\mathrm{H} 445$

Robinson BF, Epstein SE, Beiser GD, Braunwald E (1966) Control of heart rate by the autonomic nervous system: studies in man on the interrelation between baroreceptor mechanisms and exercise. Circ Res 19:400-411

Roca J, Hogan MC, Story D, Bebout DE, Haab P, Gonzalez R, Ueno O, Wagner PD (1989) Evidence for tissue diffusion limitation of $\mathrm{VO}_{2} \max$ in normal humans. J Appl Physiol 67:291-299

Ronnevik PK, Nordrehaug JE, von der Lippe G (1995) Functional capacity in healthy volunteers before and following betablockade with controlled release of metoprolol. Eur J Clin Pharmacol 48:127-131

Stenberg J, Ekblom B, Messin R (1966) Hemodynamic response to work at simulated altitude, $4000 \mathrm{~m}$. J Appl Physiol 21:15891594

Van Baak MA, Jennen W, Muijtjens A, Verstappen FT (1985) Effects of acute and chronic metoprolol administration during submaximal and maximal exercise. Int J Sports Med 6:347352

Vanhees L, Fagard R, Amery A (1988) Effect of calcium channel blockade and beta-adrenoceptor blockade on short graded and single-level endurance exercises in normal men. Eur J Appl Physiol 58:87-91

Vanhees L, Defoor JG, Schepers D, Lijnen P, Peeters BY, Lacante PH, Fagard RH (2000) Effect of bisoprolol and atenolol on endurance exercise capacity in healthy men. J Hypertens 18:35-43

Verstappen FT, Van Baak MA (1987) Exercise capacity, energy metabolism, and beta-adrenoceptor blockade. Comparison between a beta 1-selective and non-selective beta blocker. Eur J Appl Physiol 56:712-718

Xie A, Skatrud JB, Puleo DS, Morgan BJ (2001) Exposure to hypoxia produces long-lasting sympathetic activation in humans. J Appl Physiol 91:1555-1562

Yamamoto Y, Hoshikawa Y, Miyashita M (1996) Effects of acute exposure to simulated altitude on heart rate variability during exercise. J Appl Physiol 81:1223-1229 